\begin{tabular}{|c|c|}
\hline UÁQUIRI & RPG \\
\hline Revista do Programa de Pós-Graduação em Geografia \\
UÁQUIRI - PPGGEO, v. 2, n. 2, p. 43-60, ano 2020
\end{tabular}

\title{
TRABALHO DOCENTE NO CAMPO: INTERFACES ENTRE FORMAÇÃO E IDENTIDADE DOS PROFESSORES DE GEOGRAFIA
}

\author{
Juliana Santos de Souza Cunha ${ }^{1 *}$, Silvio Simione da Silva ${ }^{2}$. \\ ORCID: https://orcid.org/0000-0002-6980-3114; https://orcid.org/0000-0001-5348-9899
}

\begin{abstract}
${ }^{1}$ Discente do Programa de Pós Graduação em Geografia pela Universidade Federal do Acre, Rio Branco, Acre, Brasil.; ${ }^{2}$ Professor do Dr. da Universidade Federal do Acre e Coordenador do Programa de Pós-Graduação em Geografia, Rio Branco, Acre, Brasil.

* julisantos510@gmail.com
\end{abstract}

Recebido em: 15/10/2020 Aceito em: 16/11/2020 Publicado em: 20/12/2020 DOI: https://doi.org/10.47418/uaquiri.vol2.n2.2020.4382

\begin{abstract}
RESUMO
Este artigo é parte de uma construção conceitual, que procurou se basear nas discussões sobre trabalho docente no campo: interfaces entre formação e identidade dos professores de Geografia. Tem como objetivo analisar a formação e a construção da identidade profissional dos professores do campo, apoiando-se em referenciais teóricos de caracterização dos modelos profissionais e como esse se relaciona com a construção da identidade do professor. Esse trabalho baseou-se na análise e aprofundamento de referenciais teóricos, bem como nas questões, que são parte do estudo dessa pesquisa sobre educação do campo. Desse modo, as discussões apresentadas são fruto de uma aproximação teórica inicial, visando elencar elementos teóricos sobre as características que compõem a identidade do professor de Geografia, com bases concretas para essa formação.
\end{abstract}

Palavras-Chave: Formação; identidade; Geografia; educação do campo; trabalho docente.

\section{TEACHING WORK IN THE FIELD: INTERFACES BETWEEN TRAINING AND IDENTITY OF GEOGRAPHY TEACHERS}

\begin{abstract}
This article is part of a conceptual construction, which sought to be based on discussions about teaching work in the field: interfaces between training and identity of geography teachers. It objectives to analyze the formation and construction of the professional identity of teachers in the field, relying on theoretical references of characterization of professional models and how this relates to the construction of the teacher's identity. This work was based on the analysis and deepening of theoretical references, as well as on the questions, which are part of the study of this research on field education. Thus, the discussions presented are the result of an initial theoretical approach, aiming to list theoretical elements about the characteristics that make up the identity of the geography teacher, with concrete bases for this formation.
\end{abstract}

Keywords: Training; Identity; Geography; Field education; Teaching work. 


\title{
TRABAJO DOCENTE EN EL CAMPO: INTERFACES ENTRE FORMACIÓN E IDENTIDAD DE LOS MAESTROS DE GEOGRAFÍA
}

\begin{abstract}
RESUMEN
Este trabajo forma parte de una construcción conceptual, que buscó basarse en las discusiones sobre trabajo docente en el campo: interfaces entre formación e identidad de los maestros de Geografía. Tiene por objetivo analizar la formación y la construcción de la identidad profesional de los maestros del campo, apoyándose en referenciales teóricos de caracterización de los modelos profesionales y cómo este se relaciona con la construcción de la identidad del profesor. Ese trabajo se basó en el análisis y profundización de referenciales teóricos, así como en las cuestiones que son parte del estudio de esta pesquisa sobre educación de campo. De ese modo, las discusiones presentadas son fruto de un acercamiento teórico inicial que busca enumerar elementos teóricos sobre las características que componen la identidad del profesor de Geografía, con bases concretas para esa formación.
\end{abstract}

Palabras-Clave: Formación; Identidad; Geografia; Educación de Campo; Trabajo Docente.

\section{INTRODUÇÃO}

Este trabalho visa discutir e identificar as mudanças recentes no desenvolvimento do trabalho docente, diante das políticas educacionais iniciadas no final do século XX e início do século XXI, discutir como essas transformações recentes impactaram na autonomia profissional dos professores, no desenvolvimento de seu trabalho, na formação de uma identidade profissional e nas visões que são constantemente construídas por diversos meios, sobre como deve ser o perfil do professor de Geografia nesta perspectiva de mudanças estruturais.

Nesta linha de análise, primeiramente propõe-se uma discussão sobre o trabalho docente e a construção de uma identidade profissional, discutindo quais são as novas exigências diante desse quadro de reformas. Como os professores reagem a essa intensificação e precarização de seu trabalho, bem como, vão se construindo as identidades desses sujeitos, no âmbito pessoal e social. Em seguida, apresentam-se alguns modelos e discussões sobre a profissionalização docente, suas características e como isso vai se delineando diante das novas exigências profissionais. Portanto, é um esboço teórico que procura se basear nas discussões sobre o trabalho docente e a construção da identidade dos professores do campo.

$\mathrm{Na}$ discussão sobre as identidades formadas pelos professores do campo, busca-se relacionar esse perfil profissional com as demandas e as diversas representações que são atribuídas aos professores em escolas no campo. É, por isto, um estudo de pesquisa em fase inicial, portanto, as discussões que serão apresentadas, é fruto de uma primeira aproximação, uma busca por identificar que aspectos teóricos e práticos permeiam o trabalho do professor em escolas no campo, que elementos territoriais são inseridos em sua prática cotidiana e, como isso poderá representar uma formação indenitária diferenciada dos professores da cidade. 
$\mathrm{Na}$ análise da Geografia como conhecimento básico e prático para o ensino do campo buscou-se a compreensão de seu papel e importância para promoção de conhecimentos que formem alunos conscientes e críticos preparados para lidar com as diferenças e diversas formas de abordagens dos conteúdos na sua vivencia e no seu espaço, a partir das especificidades do lugar (campo) onde são estabelecidas suas práticas sociais coletivas.

Com vistas a desenvolver tal discussão, entende-se que não se pode chegar a uma conclusão sobre esse assunto, ainda mais em uma fase inicial. Porém, busca-se uma perspectiva de contribuir para o desenvolvimento do tema em questão, no aguçamento da investigação sobre um tema relativamente novo que é a Educação do Campo, vinculando-o a um processo de construção social e coletiva que é o processo de formação e trabalho docente.

\section{FORMAÇÃO DO PROFESSOR E A CONSTRUÇÃO DA IDENTIDADE PROFISSIONAL}

Diante das transformações sociais do final do século XX e início do século XXI, a partir do avanço do neoliberalismo, o processo de globalização, que culminou com reformas em diversos âmbitos. Propõe-se aqui, analisar as mudanças ocorridas com as políticas de reformas educacionais e como elas impactaram e continuam impactando ao atingir a formação do professor, a natureza do trabalho que ele desenvolve e no processo de formação de sua identidade profissional, quais as permanências e descontinuidades do papel do professor diante da educação em tempos de globalização.

Diante dessas políticas de reformas educacionais, percebe-se muito mais o aumento da intensificação do trabalho do professor, do que mesmo uma real autonomia e participação no processo de gestão democrática, como aponta Oliveira:

\footnotetext{
$\mathrm{O}$ trabalho docente deve contemplar as atividades em sala de aula, as reuniões pedagógicas, a participação na gestão da escola, o planejamento pedagógico, dentre outras atividades. Esse quadro tem resultado em significativa intensificação do trabalho e precarização das relações de emprego, em mudanças que repercutem sobre a identidade e profissão docente (2008, p. 30).
}

Cabe a partir deste trecho, compreender que o processo de gestão democrática e a série de mudanças conjunturais da educação, sobrecarregam e orientam a prática do professor para uma situação de constante cobrança, um processo de ensino-aprendizagem baseado em resultados. Nesse contexto de sobrevivência escolar e desenho profissional, as configurações dos perfis profissionais são exigentes, enquanto o processo de valorização profissional e construção de uma identidade coletiva tornam-se cada vez mais vagas. 
Ao identificar tais mudanças ocorridas no interior das escolas, o processo de reformulação de seus conteúdos, o sistema de avaliação em larga escala, todas essas são questões que refletem diretamente na organização e finalidade do trabalho do professor. Para este como profissional da educação, torna-se importante observar diferentes caminhos e processos que ainda convivem e imperam na formação da identidade e na prática profissional. Ao passo, que se destacam esses elementos da profissão docente, Hypólito (1991), destaca algumas mudanças quando este trata do processo de trabalho na escola.

\begin{abstract}
No Brasil, neste século especialmente, a escola passou por uma série de modificações que refizeram o seu perfil em termos de estrutura e organização. Apesar dessas modificações nem sempre se mostram aparentes, substancialmente a escola transitou de um modelo tradicional, que a caracterizava pela autonomia do professor em relação ao ensino e à organização escolar e por processos burocráticos praticamente inexistentes, para um modelo técnico-burocrático, caracterizado pela redução da autonomia do professor em relação ao ensino e à organização da escola - divisão de tarefas, formas de controle, hierarquização - enfim, por uma marca burocrática muito acentuada (HYPOLITO, 1991, p.4).
\end{abstract}

Aqui são evidenciadas algumas das mudanças significativas da escola, do modelo educacional e por fim o papel do professor diante dessas mudanças. A diminuição da autonomia do professor é notória em relação a essa questão. Ainda neste contexto, destaca-se outro aspecto relevante dessa discussão, em paralelo à redução da autonomia do professor, cresce a exigência de sua profissionalização, bem como suas responsabilidades diante dos resultados alcançados pelos alunos.

No âmbito destas mudanças estruturais da escola, configura-se construção da identidade do professor, que perpassa por questões que vão além dessas reformas, ela é construída sob as bases de uma sociedade capitalista, mas que se relaciona com a personalidade e a construção coletiva que permeia a profissão e o caráter de seu trabalho. Sobre isto, Nóvoa (1998), afirma que Os professores não são apenas consumidores, mas também produtores de saber. Os professores não são apenas executores, mas são também criadores de instrumentos pedagógicos. Os professores não são apenas técnicos, mas são também profissionais críticos e reflexivo.

No aspecto de construção da identidade docente pelas questões sociais que envolvem o exercício da profissão, encontra-se o nível de formação, o alcance cultural que possuem os professores e as formas de relacionamento que desenvolvem no trabalho, constituindo assim, diferentes maneiras de entender o processo educacional e a relação deste com outros âmbitos sociais. Desse modo, Gatti (1996), nos apresenta a construção de uma identidade que se faz a 
partir de bases concretas e não num processo de objetivação, num processo unicamente técnico, como apontam as pesquisas que valorizam as reformas educacionais mais recentes.

[...] o professor é uma entidade abstrata, um protótipo idealizado como muitas vezes o vemos tratado na pesquisa, em textos reflexivos em educação, ou em documentos de políticas ou intervenções educacionais. Ele é uma pessoa de certo tempo e lugar. Datado e situado, fruto de relações vividas, de uma dada ambiência que o expõe ou não saberes, que podem ou não ser importantes para sua ação profissional. E é assim que precisa ser compreendido (GATTI, 1996, p. 88).

É através dessa abordagem que a autora apresenta a construção da identidade do professor a partir de dois aspectos: "o pessoal e o social” (GATTI, 1996, p. 88), neste caminho que se constrói a identidade docente diante da heterogeneidade de experiências por eles vivenciadas. Ao realizar esse movimento do pessoal e do coletivo, a profissionalização do professor, traz para sua prática alguns elementos que intermediam a sua interação com os alunos, com o modo de ensinar e mesmo estando pautado em um processo de formação superior, é necessário reconhecer que a as aspirações, as convicções e o modo como os professores lidam com a educação muito tem a ver com essa construção da sua identidade.

É importante ressaltar que, mesmo sujeitos com identidades e perfis profissionais diferentes, os professores no Brasil, são fruto de alguns processos históricos semelhantes, que os reúnem em uma classe social, sem que, no entanto, isso esteja bem claro a estes sujeitos. A predominância do gênero feminino no magistério, a forma como estes chegaram à formação universitária, como a docência é vista uma das poucas formas de ascensão social e profissional e até mesmo a questão de compreender o magistério como uma atividade transitória e em outros casos complementar. Estas podem ser algumas das semelhanças encontradas em algumas pesquisas realizadas sobre o perfil dos professores (OLIVEIRA, 2004, 2008; GATTI, 1996; HYPOLITO, 1991), esses aspectos, associados às reformas educacionais mais recentes, suscitam questões para entender a formação e a construção da identidade dos professores em suas práticas profissionais.

Diante da discussão sobre as diversas formas de se reconhecer os diferentes reconhecimentos sobre a profissão docente e as identidades dos professores, Garcia; Hypólito e Vieira (2005) nos mostram alguns modelos de profissionalismos que são gerados sobre a imagem do professor e sua representação social. Tais modelos constituem: o profissionalismo clássico, profissionalismo como trabalho flexível, profissionalismo como trabalho prático, profissionalismo como trabalho extensivo, profissionalismo como trabalho complexo. São discutidos, a partir desses modelos, as questões da profissão docente, desde o status 
profissional, ás questões práticas da sala de aula, a flexibilização do trabalho, à vocação profissional, entre outros elementos que compõem esse processo de formação profissional e como isso resvala na construção de uma identidade.

Ainda nesta discussão os autores destacam e enfatizam como a construção do profissional docente, pode ser fonte de diversas perspectivas dentro da sociedade, bem como nos chama a atenção sobre a fragmentação do trabalho do professor e como isso pode gerar uma precariedade daquilo que é essencial em seu processo de trabalho, que é o ensinoaprendizagem.

Diante dos modelos profissionais mencionados acima, é possível perceber que existe uma visão externa que é veiculada ao professor, como um ideal de sua formação e atuação profissional. Essas perspectivas em torno do papel do professor são construídas sob diversos pontos de vistas e sob diferentes discursos sobre quem deve ser o professor. Assim, Garcia, Vieira e Hypólito, afirmam:

\begin{abstract}
A identidade docente é negociada entre essas múltiplas representações, entre as quais, e de modo relevante, as políticas de identidade estabelecidas pelo discurso educacional oficial. Esse discurso fala da gestão dos docentes e da organização dos sistemas escolares, dos objetivos e das metas do trabalho de ensino e dos docentes; fala também dos modos pelos quais são vistos ou falados, dos discursos que os vêem e através dos quais se vêm produzindo uma ética e uma determinada relação com eles mesmos, que constituem a experiência que podem ter de si próprios $(2005$, p. 47).
\end{abstract}

Por essas percepções, pelas projeções que são realizadas no contexto de desenvolvimento de um perfil profissional, a natureza de seu trabalho, a finalidade do processo de ensino-aprendizagem são atrelados ao discurso oficial e às demandas que o Estado impõe sobre o trabalho do professor. Além disso, altera os aspectos de uma autonomia profissional e mantêm esse perfil sob uma forma de coerção velada, no qual as representações e as identidades dos professores estão sempre sendo relacionadas a esses fatores externos.

Mediante essa situação, é atribuído aos professores o fracasso escolar, a evasão e o resultado das avaliações externas. Essas são algumas das questões que surgem e interpelam os professores em diferentes níveis de ensino.

Com todo esse processo de demandas profissionais e discursos - em muitos casos idealizadores - do papel do professor, é compreensível que existam múltiplas visões do próprio professor em relação à sua identidade profissional e o seu reconhecimento enquanto parte de uma construção coletiva. Distanciam-se o entendimento das questões contextuais que estão 
atreladas a escola e todo o processo educacional brasileiro, portanto, as dimensões políticas, o reconhecimento de classe, tornam-se um tanto distantes da representação social do professor.

Porém, não se pode negar que, apesar dessa identidade carregada de muitos simbolismos, os professores também possuem elementos próprios no conjunto de saberes e representações que desempenham em suas práticas cotidianas. Esses aspectos formam um conjunto cultural dinâmico, fruto de uma construção social coletiva e também pessoal. Através de suas histórias e formas de ensinar, vão criando traços de sua identidade e experiências profissionais, que não são capazes de ser apreendidas em um único modelo de profissionalismo. Assim,

O saber profissional compõe, portanto, um aspecto essencial do conteúdo da profissionalidade docente e pode tornar mais eficaz a ação educativa do professor. Torna-se evidente a importância da subjetividade do professor no desenvolvimento de seu trabalho e uma abertura, sempre necessária, ao movimento histórico (LOPES, 2010, p. 40).

Essa construção indenitária torna-se ainda mais evidente quando se trata de práticas docentes vinculadas ao espaço do campo, que constitui a perspectiva de análise deste trabalho. Com isso, busca-se entender como se relacionam a formação profissional e a construção da identidade docente, sob a ótica de uma pedagogia que se desenvolve no campo. Existem elementos que possam conduzir a uma investigação sobre uma identidade dos professores do campo? O processo de formação docente e a prática docente no campo, como se constitui uma identidade a partir dessa relação?

\section{EDUCAÇÃO DO CAMPO: O PROCESSO DE FORMAÇÃO E A CONSTRUÇÃO DE UMA IDENTIDADE DOCENTE.}

Esta análise é fruto de uma pesquisa em fase inicial, que busca compreender o papel da escola do campo e a partir disso, entender qual a representação dos professores que trabalham em escolas no campo.

A educação do campo é um conceito que não se fecha nele mesmo, pois incorpora a própria dinâmica dos movimentos sociais do campo e intelectuais que se dedicam á questão agrária brasileira, aos problemas da exclusão social, da distribuição desigual da terra e da renda aos problemas de soberania alimentar, das patentes, entre outros (JESUS, 2004; MOLINA, 2004).

A pesquisa sobre educação do campo é um caminho relativamente novo, pois se trata de uma concepção sob a ótica das questões que envolvem o campo brasileiro, as questões do 
acesso a terra e como a educação representa um direito, mas, numa perspectiva integradora e significativa para os moradores das áreas rurais. Assim,

\begin{abstract}
Compreende-se que a organização da escola do campo também se articula à consolidação de uma concepção de escola no e do campo, isto é, de uma educação que seja pensada para a realidade dos povos do campo brasileiro. Assim, além do dever de garantir o acesso ao processo de escolarização e os conhecimentos historicamente produzidos pela humanidade, a escola do campo mostra-se fundamental para a manutenção e para o avanço da luta pela terra, para a compreensão da identidade do sujeito coletivo do campo e para a construção de um projeto de escola que se integre a um projeto de transformação social (LIMA; COSTA; PEREIRA, 2017, p. 1130).
\end{abstract}

Nesta perspectiva, a educação do campo faz-se num processo de construção de um saber significativo para a comunidade em que ela encontra-se inserida. Nesse processo de ressignificação da escola do campo, quais relações os professores desenvolvem com a escola? Como se desenvolvem as práticas educacionais no campo? De que forma e sob quais condições o trabalho é efetivado?

Assim, entende-se que a construção de uma identidade dos professores que trabalham em escolas no campo, perpassa por questões que envolvem as relações com as comunidades e o modo como organizam seu trabalho pedagógico, relacionando-o ou não, com os espaços em que estão inseridos.

Chervel (1990), afirma que o papel da escola não se limita ao exercício das disciplinas escolares. Essas constituem uma parte da educação escolar. Considera ainda, que as finalidades da educação escolar não estão forçosamente inscritas nos textos, mas, de certa forma, colocadas em posição antagônica entre o lado da lei, da prescrição institucional, das práticas concretas e desenvolvidas no cotidiano.

Quando são relacionados a uma perspectiva regional, existem especificidades que envolvem os professores do campo, tem-se historicamente um processo de desigualdade no perfil formativo, dado as questões de acesso a uma formação universitária que anteriormente foi bastante dificultada e devido às políticas de reformas educacionais mais recentes, tornou-se uma exigência que acabava sendo inserida gradativamente, levando muitos professores do campo a necessidade de adquirirem formação superior.

Neste caso, a formação é adquirida em processos posteriores à prática, a construção de saberes que foram, ao longo de muitos anos sendo construídos, em alguns casos em um processo de dupla função - a de produtor rural familiar e de professor - que não podem ser ignorados no processo de formação destes sujeitos. 
Além destes, existem outros aspectos a serem observadas, as múltiplas funções que o professor desenvolve na escola, que vão desde a gestão administrativa à limpeza e cuidado com a merenda dos alunos, para além dessas práticas, existe a multiseriação, que constitui um fator relevante na organização do trabalho pedagógico do professor.

Entre esses aspectos já citados, acrescentam-se as distâncias que são percorridas até o local de trabalho, o perfil da turma que envolve sujeitos de diferentes idades e graus de aprendizagem. Essa relação com o campo, com os sujeitos do campo, exige uma organização do trabalho pedagógico, que esteja em conformidade com as peculiaridades do lugar. São questões que estão postas no perfil da coletividade, num olhar mais solidário para estas questões, isso reflete na forma de pensar a educação e a formação desses sujeitos do campo.

Relacionando alguns destes fatores, é importante ressaltar que as diversas dimensões que representam ser um professor do campo, envolvem questões políticas e saberem teóricos e práticos que precisam ser investigados com profundidade, não podendo respondê-lo de maneira imediata e a partir de generalizações, visto que a identidade dos professores do campo delineiam questões desde os saberes práticos por eles construídos ao longo de seu trabalho, ao processo de formação inicial, assim como as representações políticas que esses sujeitos representam para a escola do campo.

No esteio de uma nova concepção pedagógica, a qual assumem as escolas do campo, torna-se fundamental entender em quê a natureza do trabalho do professor se diferencia da do professor da cidade. Pois, a natureza deste paradigma educacional, envolve a construção de um currículo, de um projeto político pedagógico e de uma construção de saberes que envolvem a coletividade.

É importante pontuar que toda prática pedagógica deve fundar-se na visão de mundo e de ser humano que se pretende formar. A educação do campo tem em seu projeto educativo o objetivo de formar um sujeito que não é estático, ao contrário, está sempre em movimento, porque é coletivo (LIMA; COSTA; PEREIRA, 2017, p. 1137).

Aqui, demonstram-se o parâmetro que este paradigma educacional leva em consideração, que é a questão dos saberes escolar como um direito à comunidade, mas construída a partir dela, ou seja, na coletividade. Para esse entendimento é preciso assumir a educação como um processo político, que busca defender os interesses e a autonomia das populações que residem no campo, destacando sobremaneira as suas formas de vida e legitimando a dimensão social que eles representam. Nesta perspectiva, o professor torna-se parte desse processo de luta pela afirmação dos trabalhadores rurais, a escola passa a ser um 
local privilegiado para essa tomada de consciência, é, portanto necessário um entendimento do papel político que os professores representam nestes locais.

\begin{abstract}
Como aproximar essa riqueza teórica tão radical com o fazer pedagógico possível dos docentes-educadores/as tão limitados na estreiteza da materialidade física das escolas? Dando centralidade a pesquisar com prioridade e produzir análises sobre os processos políticos que produziram em nossa história e continuam produzindo essa inexistência de um sistema público de educação no campo e nos territórios indígena, quilombola. O conhecimento dessa história deverá ser incorporado nos currículos de formação de professores/as e dos trabalhadores (ARROYO, 2015, p. 51).
\end{abstract}

Muito embora, essa construção de uma identidade coletiva possa se formar nos professores do campo, nem sempre esse processo é consciente, articulado a uma reflexão mais aprofundada de sua prática. Esses podem ser elementos constituintes de sua prática pedagógica, sem levar em consideração a dimensão política em que esse processo está inserido. Que podem ser adquiridas a partir de um processo de formação inicial que forneça bases teóricas e reflexivas para esse exercício, estas são algumas das concepções da Educação do Campo.

Outra proposição pode ser relativa a essa discussão, que é o distanciamento ou o estranhamento dessas relações da Educação do Campo, neste caso, admite-se uma prática descontextualizada desses locais e que assume um processo educativo sob as bases urbanas, apenas como um aspecto do direito a educação, aos saberes historicamente produzido, mas que não possuem elementos da dimensão política que representam as questões de luta pela terra e afirmação dos modos de vida desses moradores do campo.

\footnotetext{
Na perspectiva desses ordenamentos curriculares fica difícil encontrar espaços para currículos dos trabalhadores/as do campo, indígenas, quilombolas que incorporem a radicalidade com que os "diferentes" se afirmam em suas lutas políticas sociais e culturais pela educação e pelo conhecimento (ARROYO, 2015, p. 57)
}

Ao assumir este aspecto, os professores podem ter uma formação inicial que seja preponderante em sua prática, neste caso, em alguns Estados já concentram a formação inicial dos professores com vistas às práticas pedagógicas do campo, mas na ausência disso, a prática docente e a construção de uma identidade docente, pode não estar relacionada às dimensões políticas e práticas já mencionadas.

Outro fator que está relacionado a este contexto educacional pode ser a formação de uma base educacional comum (BNCC), nisto, pode-se ressaltar a necessidade de os professores e alunos do campo, priorizarem os conteúdos ditos "formais", pela questão de equiparação de conhecimentos, de habilidades, que possam ser adquiridos também nas escolas mais distantes. 
Isso pode ser uma concepção crítica, que vê a escola como local de acesso a um conhecimento cultural de reconhecimento em toda a sociedade. Porém a interseção das bases culturais formais e o reconhecimento de outras culturas poderão servir de caminho para a construção de uma identidade mais sólida, entre professores e alunos.

\footnotetext{
A Educação do Campo é por essência transversal. Ela é um meio de formação que nasce de um compromisso em reconhecer os sujeitos, recuperar a sua identidade como trabalhador ou trabalhadora do campo, o campo como espaço vivido, dar visibilidade a diferentes vozes e experiências, enfim, criar alternativas de construção de outro tipo de conhecimento e de prática emancipatória. (MOLINA, 2004, p. 126).
}

Por isso, sabemos que a Educação do Campo não se desenvolve sozinha, é necessária a inter-relação com o Estado para que se possam socializar as formas de produção de conhecimentos alargadas com as questões da terra. E nesse contexto, é importante esse processo investigativo das identidades dos professores do campo, levar em consideração das multiplicidades de situações que envolvem o campo brasileiro, que vão desde as desigualdades sociais presentes nas áreas rurais, ao acesso a estes locais, o processo de trabalho desenvolvido em comunidade, os movimentos sociais de luta pelos direitos a terra, bem como, qual a relação destes com a formação da identidade docente.

\footnotetext{
O movimento da Educação do Campo amplia esta perspectiva ao entrelaçar na proposta da identidade de campo uma diversidade de sujeitos sociais que vivem numa realidade social complexa de espaços, nas formas de produção e no pertencimento étnico-racial. (NASCIMENTO; RODRIGUES; SODRÉ, 2013, p. 50).
}

As construções coletivas são um ponto de partida para o entendimento dessas identidades dos professores do campo, buscando um processo de relações que vão além do espaço escolar, que possuem relações com a comunidade, com o trabalho e com os diferentes espaços que permeiam o desenvolvimento do trabalho pedagógico dos professores do campo. Essa análise torna-se uma busca pela identificação, das composições sociais, políticas e até econômicas que constroem o processo educativo dos sujeitos do campo.

\section{A GeOgrafia COMO CONHECIMENTO BÁSico E PRÁtico PARA O ENSINO NA EDUCAÇÃO DO CAMPO}

O ensino de Geografia é fundamental para transformar os conhecimentos básicos dos alunos do campo em conhecimentos práticos, tornando-os capazes de transformar e dar sentido 
ao seu espaço de vivencia cotidiano. À medida que se adquiri conhecimento e põe em prática pelo processo de formação humana, os sujeitos se tornam elementos essenciais para a consolidação e transformação da vida construindo e reconstruindo sua identidade, cultura e o trabalho coletivo de forma mais crítica e consciente dentro e fora de suas comunidades.

Segundo Cavalcanti (2012, p. 112), "um ensino de cunho crítico, voltado para o desenvolvimento intelectual dos alunos, busca mediar seus processos de capacidades de pensamento, já portadores de histórias e sensibilidades, de experiências reais e imaginárias". Sendo assim, a geografia é uma disciplina que tem grande potencial de elevar o conhecimento dos sujeitos do campo por sua praticidade de informações relevantes aos conceitos que envolvem o dia - a - dia dos alunos que vivem não só na cidade, mas, principalmente no campo. Pois "a formação do pensamento conceitual, que permite uma mudança na relação do sujeito com o mundo, generalizando suas experiências, é papel da escola e das aulas de geografia". (CAVALCANTI, 2012, p. 165).

Diante do exposto pela autora, podemos compreender que a Geografia em sua intima relação com a escola, além de serem fundamentais na formação de conceitos, valores e atitudes para a vida prática dos alunos do campo é também grande influenciadora na aquisição de conhecimentos através das experiências ligadas ao mundo vivido.

De acordo com Cavalcanti (2013, p. 25), através da Geografia o aluno pode realizar "a leitura de mundo do ponto de vista de sua espacialidade" relacionando seu ambiente de vivencia cotidiano com outros conceitos (lugar, paisagem, território e região) que formam um grande conjunto de interpretação da realidade socioespacial presente no ensino de geografia e que se torna elemento importante na aquisição de um conhecimento básico e prático para a formação cognoscitiva dos alunos do campo. Corroborando ainda com essa idéia Cavalcanti (2013, p. 149), afirma que “[...] de nada serve o conhecimento propiciado pelo ensino se não tiver resultados na vivência prática. E, é nesse ponto que se deve destacar a ligação da aprendizagem dos conceitos, formação de atitudes, valores e de convicções para a vida cotidiana".

O aluno do campo tem em sua realidade escolar elementos que diferem da realidade escolar da cidade. Sua estrutura de vida, cultura, práticas sociais, trabalho familiar, etc, tem uma relação direta com as práticas sociais desenvolvidas dentro de sua comunidade e o que se aprende na geografia e na escola, por essa e outras razões, se tornam essênciais na produção do conhecimento desses sujeitos.

O ensino de geografia deve ser proporcionado na escola como uma forma de socialização de conhecimentos de vivencias entre professores, gestores, famílias, etc, pois 
promovem conhecimentos básicos e práticos para a formação desses sujeitos desenvolvendo sua capacidade de raciocínio lógico, crítico, formadores de opinião e éticos.

Segundo Caldart (2004, p. 40):

\begin{abstract}
A escola socializa a partir das práticas que desenvolve; por meio do tipo de organização do trabalho pedagógico que seus sujeitos vivenciam e das formas de participação que constituem seu cotidiano. São as ações que revelam as referências culturais das pessoas, educandos e educadores. E é trazendo à tona estas referências que elas podem ser coletivamente recriadas e reproduzidas.
\end{abstract}

Mediante essa informação, podemos observar que a escola e seus processos formativos na socialização e reflexão do que acontece na vida cotidiana do aluno do campo, tem grande poder de transformação e recriação de novos sujeitos e suas culturas em seu território.

Conforme Fernandes e Molina (2004, p. 61):

Os povos do campo e da floresta têm como base de sua existência o território, onde reproduzem as relações sociais que caracterizam suas identidades e que possibilitam a permanência na terra. E nesses grupos há forte centralidade da família na organização não só das relações produtivas, mas da cultura, do modo de vida. Esses grupos sociais para se fortalecerem, necessitam de projetos políticos próprios de desenvolvimento socioeconômico, cultural e ambiental. E a educação é parte essencial desse processo.

Portanto, a geografia como parte importante nesse processo de formação do cidadão consciente e capaz de estabelecer relação de reciprocidade dentro de seu território de formação e identidade. Bem como, promover uma forma de aquisição de conhecimentos que atendam as especificidades desses sujeitos do campo, a fim de que os mesmos possam não só fortalecer seus laços familiares e culturais, mas também, possam ser alcançados através de políticas públicas governamentais que auxiliem no desenvolvimento e fortalecimento da educação como um todo.

Segundo Medeiros (2010, p. 1):

O ensino da Geografia na educação básica possibilita reflexões e ações sistematizadas dos educandos sobre o espaço vivido, desse modo, o saber geográfico contribui para o desenvolvimento da identidade e da autonomia da criança diante da sociedade e de seu ambiente.

Conforme a fala do autor, podemos compreender com isso, que o ensino da Geografia fortalece a formação da identidade do lugar e de convívio do aluno através das relações 
familiares, amigos, lazer e, principalmente, com a comunidade escolar, formadores de valores, solidariedade e que serve de fortalecimento da identidade espacial desses sujeitos.

Daí a importância da Geografia como conhecimento básico e prático, principalmente na educação do campo, porque a necessidade de rever conceitos que não estão presentes nas ações didático-pedagógicas propostas para o ensino de geografia nas escolas do campo. Sendo assim, a vida e as relações cotidianas dos sujeitos do campo são elementos que devem ser considerados no ato de ensinar geografia, principalmente diante da entrada de tecnologias onde o "tempo e o espaço são continuamente desafiados" (MEDEIROS, 2010, p. 13). Portanto, devendo-se ter o cuidado com a forma metodológica e os conteúdos repassados aos estudantes.

No Brasil, os Parâmetros Curriculares Nacionais (PCNs) orientam as práticas pedagógicas do ensino de Geografia da seguinte forma:

O ensino de Geografia, de forma geral, é realizado por meio de aulas expositivas ou da leitura dos textos do livro didático. Entretanto, é possível trabalhar com esse campo do conhecimento de forma mais dinâmica e instigante para os alunos, mediante situações que problematizem os diferentes espaços geográficos materializados em paisagens, lugares e territórios; que disparem relações entre o presente e o passado, o específico e o geral, as ações individuais e as coletivas; e promovam o domínio de procedimentos que permitam aos alunos "ler" a paisagem local e outras paisagens presentes em outros tempos e espaços. (BRASIL, 2001, p. 153).

A partir dessa informação, podemos compreender que o ensino de geografia por ser dinâmico e possuir peculiaridades e complexidades em sua forma, possui várias maneiras de ser trabalhada em sala de aula e fora dela. Portanto, deve ser construída levando em consideração o dia - a - dia do aluno do campo e suas especificidades na forma de construção e reconstrução da aprendizagem. Por isso, é importante que o conhecimento geográfico seja analisado através do espaço vivido dos alunos e da observação em suas formas direta ou indireta (BRASIL, 2001).

O ensino no campo perpassa os conceitos formais a que as escolas em suas ações didático-pedagógicas estão submetidos, tendo em vista que já foram abordadas anteriormente, as especificidades dos sujeitos que vivem no campo. Dessa forma, o papel da Geografia nesse processo de construção do conhecimento cognoscitivo do sujeito do campo, é de fundamental importância para que se efetive uma educação de qualidade para todos.

Quando falamos de educação para todos, Oliveira e Campos (2012, p.238) afirmam que a: 
[...] educação básica necessita de políticas de universalização para se tornar efetivamente um direito de todos, inclusive dos povos do campo, para que os profissionais da educação e os usuários das instituições escolares se formem assegurando suas territorialidades e identidades sociais.

A educação básica proposta pelas legislações vigentes (Constituição Federal, LDB, PCNs, e recentemente a BNCC) busca preparar o aluno para o mercado de trabalho e para a vida, promovendo com isso, diversos olhares para o ensino de Geografia. Essas abordagens no geral se identificam mais com o viés da educação proposta para alunos da cidade, pois, trazem em seu contexto de formação e preparação elementos presentes no escopo do sistema capitalista globalizado em vigor. Por esse motivo, a Geografia tem o compromisso de propor para o campo um ensino diferenciado e desafiador na prática e nas formas de abordagens que levem em conta as especificidades do lugar sem deixar de lado a formação e preparação para o trabalho e para a vida.

Portanto ao analisar a importância da Geografia como conhecimento básico e prático para o ensino da educação do campo é preciso assegurar aos alunos um ensino que promova não só o conhecimento formal, mas também os conhecimentos informais que vão além do seu campo de vivencia. E com isso, promover a construção de um novo modelo de aprendizagem pautada nas práticas sociais coletivas, no trabalho familiar, na ética e na cultura dos povos que vivem e sobrevivem da floresta.

\section{CONSIDERAÇÕES FINAIS}

Cabe a este texto uma visão inicial e, portanto, não conclusiva do processo de formação e construção da identidade profissional dos professores, sob as bases da Educação do Campo. Este posicionamento busca alcançar os momentos e a natureza do trabalho pedagógico que se encontra com a dimensão territorial em que está inserido. Além disso, compreender a Geografia como formador de conhecimento básico e prático na educação do campo, processo esse que requer um olhar mais específico para desenvolver conhecimentos construídos e reconstruídos ao longo da história de vida dos sujeitos que vivem no campo.

Nestes aspectos, apresentou-se a forma e a importância da identidade do professor diante dos desafios das reformas políticas educacionais e posteriormente, analisar como o campo pode contribuir para um processo de consciência de uma educação e um trabalho pedagógico 
relacionado às questões coletivas, na constituição do papel do professor, que assume uma dimensão política de luta pelas causas sociais que movem os trabalhadores do campo.

Sob o prisma de bases teóricas, ainda, pode-se admitir que esse novo paradigma político pudesses ou não ajudar na construção diferenciada e mais consciente dos professores do campo, no entanto, existem muitos aspectos que podem afastá-los desse processo, que pode ser desde o seu processo de formação inicial ou mesmo a consciência não adquirida desse caráter políticopedagógico. Nestes casos, a formação da identidade profissional deverá estar articulada ao processo histórico ao qual este professor está vinculado. Se a sua história é constituída a partir das áreas rurais, certamente que a sua identidade terá elementos propriamente deste espaço, sua prática pedagógica terá referências de seu processo familiar e comunitário. Do contrário, as bases urbanas, também podem permear a construção de uma identidade que trará a interseção desses dois espaços.

Esses são apenas alguns caminhos para a investigação, no entanto, outros são igualmente importantes como: Quem são esses professores? Qual a representação que ele assume diante das comunidades do campo? Quais as funções que ele desenvolve que estão além de sua profissão? Como é desenvolvido o trabalho pedagógico nas salas multisseridas? Todos esses, são elementos que assumem um caráter determinante na prática profissional e na construção da identidade dos professores de Geografia.

Por isso, acredita-se que estabelecer um modelo de profissionalização preponderante, não seja adequado para definir os professores do campo, visto que estes podem trazer características de diversos modelos, constituindo assim, os seus saberes, a organização de seu trabalho pedagógico e a representação que isso tem no conjunto da dimensão social em que se encontra.

\section{REFERÊNCIAS}

ARROYO, Miguel G. Os Movimentos Sociais e a Construção de Outros Currículos. Educar em Revista, Curitiba, n. 55, p. 47-68, jan/mar, 2015. Disponível em:

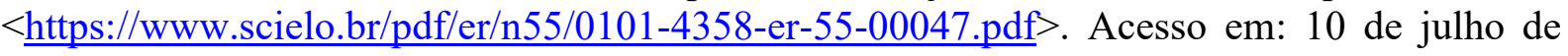
2020 .

BRASIL, Secretaria de Educação Fundamental. Parâmetros Curriculares Nacionais: História e Geografia. 3 ed. Brasília, MEC/SEF, 2001.

CALDART, Roseli Salete. Elementos para a construção de um projeto político e pedagógico da Educação do Campo. In: MOLINA, Mônica Castagna; JESUS, Sonia Meire Santos Azevedo 
de. (organizadoras). Por Uma Educação do Campo: Contribuições para a Construção de um Projeto de Educação do Campo. Brasília, DF, 2004.

CAVALCANTI, Lana de Souza. Geografia, escola e construção de conhecimentos/Lana de Souza Cavalcanti. - $18^{\mathrm{a}}$ ed. - Campinas, SP: Papirus, 2013. - (Coleção Magistério: Formação e Trabalho Pedagógico).

CAVALCANTI, Lana de Souza. O ensino de geografia na escola/Lana de Souza Cavalcanti. Campinas, SP: Papirus, 2012. - (Coleção Magistério: Formação e Trabalho Pedagógico).

CHERVEL, A. História das disciplinas escolares: reflexões sobre um campo de pesquisa. Revista Teoria e Educação, Porto Alegre, n.2, 1990.

FERNANDES, Bernardo Mançano. MOLINA, Mônica Castagna. O campo da Educação do Campo. In: MOLINA, Mônica Castagna; JESUS, Sonia Meire Santos Azevedo de. (organizadoras). Por Uma Educação do Campo: Contribuições para a Construção de um Projeto de Educação do Campo. Brasília, DF, 2004.

GARCIA, Maria Manuela Alves; HYPÓLITO, Álvaro Moreira; VIEIRA, Jarbas Santos. As Identidades docentes como fabricação da docência. Educação e Pesquisa. São Paulo, v. 31, n. 1, p. 45-56, 2005.

GATTI, Bernadete Angelina. Os Professores e suas Identidades: o desvelamento da heterogeneidade. Cadernos de Pesquisa. São Paulo, n. 98, p. 85-90, ago. 1996. Disponível em: $<$ https://publicacoes.fcc.org.br/ojs/index.php/cp/article/view/798/809>. Acesso em: 15 de Jul de 2018.

História do pensamento geográfico e epistemologia em Geografia / Paulo R. Teixeira de Godoy (org.). - São Paulo: Cultura Acadêmica, 2010.

HYPOLITO, Álvaro Moreira. Processo de Trabalho na Escola: algumas categorias para análise. Teoria \& Educação. Porto Alegre, n. 4, 1991.

LIMA, Maria Aires de; COSTA, Frederico Jorge Ferreira; PEREIRA, Karla Raphaela Costa. Educação do Campo, organização escolar e currículo: um olhar sobre a singularidade do campo brasileiro. Revista e-Currículo. São Paulo, v. 15, n. 4, p. 1127-1151, out./dez, 2017.

LOPES, C. S. O professor de Geografia e os saberes profissionais: o processo formativo e o desenvolvimento da profissionalidade. Tese apresentada á Faculdade de Filosofia, Letras e Ciências Humanas da Universidade de São Paulo, 2010. P.24-96, $<$ https://www.educadores.diaadia.pr.gov.br/arquivos/File/2010/artigos_teses/2010/Geografia/t eses_saberes_geo.pdf $>$. Acesso em 16 de agosto de 2020 .

MEDEIROS, Paulo César. Fundamentos Teóricos e Práticos do Ensino de Geografia/Paulo César Medeiros. 2 ed. Curitiba: IESDE Brasil S.A, 2010. 280 p.

MOLINA, Mônica Castagna; JESUS, Sonia Meire Santos Azevedo de. (organizadoras). Por Uma Educação do Campo - Contribuições para a Construção de um Projeto de Educação do Campo. Brasília, DF, 2004. 
NASCIMENTO, Antônio. Dias; CHAVES, Rosana. Mara. Rodrigues; SODRÉ, Maria. Dorath. Bento. (Organizadores). Educação do Campo e contemporaneidade - Salvador, EDUFBA, 2013. 346 p.

NÓVOA, A. Formação de professores e profissão docente. In: (Coord.) Os professores e a sua formação. Lisboa: Dom Quixote, 1992. ISBN 972-20-1008-5. Pp. 13-33.

NUBELIA, Moreira da Silva. RAIMUNDO, Freitas Aragão. A Observação como Prática Pedagógica no Ensino de Geografia Geosaberes. Revista de Estudos Geoeducacionais, vol. 3, núm. 6, Jul/dic, 2012, pp. 50-59.

OLIVEIRA, Dalila Andrade. O trabalho docente na América Latina: identidade e profissionalização. Revista Retratos da Escola, Brasília, v. 2, n. 2-3, p. 29-39, jan/dez. 2008.

OLIVEIRA, Lia Maria Teixeira de. CAMPOS, Marília. Educação Básica do Campo. In: CALDART, Roseli Salete, et al. (orgs,). Dicionário da Educação do Campo. Rio de Janeiro: Escola Politécnica de Saúde Joaquim Venâncio, Expressão Popular, 2012. 